\title{
The Role Of Realistic Job Previews And Expectation Lowering Procedures For Expatriate Managers
}

Michael G. Harvey, (E-mail: mharvey@bus.olemiss.edu), University of Mississippi \& Bond University (Australia) M. Ronald Buckley, (E-mail: mbuckley@ou.edu), University of Oklahoma Milorad M. Novicevic, University of Mississippi

\begin{abstract}
The purpose of this paper is to integrate research from the fields of economics, management and consumer satisfaction in an attempt to better understand the nature of expectations and the process of their formation in realistic job previews (RJP) and expectations lowering procedures (ELP) methods of influencing the development of realistic expectations about a position and an organization. The approach to the paper development is to initially review the research regarding met expectations and expectation formation, while later to introduce Expectation Disconfirmation Theory and relate it to both RJP and ELP. Borrowing from the aforementioned diverse areas, a model is developed containing a continuum of expectations, disconfirmation, satisfaction and turnover intention that provides some insight, from a theoretical perspective, why RJP and ELP frequently result in successful and positive organizational outcomes. "We fear things in proportion to our ignorance of them." (Titus Livius)
\end{abstract}

\section{INTRODUCTION}

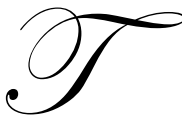

he introduction of Realistic Job Previews (RJP) into the management literature by Wanous (1973) was a watershed event in the strategic recruitment of individuals into organizations. Simply put, organizations are able to provide pre-entry, orientation, and socialization processes that successfully lower expectations, increase job satisfaction, commitment and decrease turnover when applied to expatriate managers. The basic conceptual foundation of Wonous's original insights into RJP is that employers should provide job candidates with realistic information about a job and its context, including the positive and negative aspects of an organization and a position. These RJP become extremely important in unique situations/context or when the job is difficult to delineate the parameters of the position to be filled. Both of these conditions are frequently at work during expatriate assignments.

Providing realistic information about an overseas assignment, particularly one that is as complex and unique as an expatriate assignment, has been shown to elicit positive organizational outcomes, including higher levels of job satisfaction and commitment and lower levels of turnover (Wanous, 1980). Individuals are able to incorporate/integrate this realistic information about the context of the new position as well as gain insight into the difficulties to be faced during an overseas assignment. This is of particular importance when one considers the level of adjust their expectations for a position in a foreign assignment of an expatriate manager. This level of adjustment requires a cognitive process wherein expatriates must incorporate information into their decision processes and decide upon the degree to which their expectations need adjustment to the international context of their new position.

In an attempt to provide a person-based rather than a job-based method to adjust expatriate managers' expectations about positions/organizations, one can look to the earlier work of Buckley, Fedor, Veres, Wiese and Carraher (1998) which develop an intervention means referred to as Expectation Lowering Procedures (ELP). The purpose of an ELP is to lower the expectations that an expatriate manager prior to organizational entry and/or during organizational orientation and socialization in a foreign country. Unlike an RJP, an ELP consists of information that is 
not job-specific (i.e., ELP is focused on the newcomer individual selves and the potential difficulty in adjusting to the new overseas assignment). Importantly, as ELPs do not require job-specific information, they can be more efficiently administered across jobs in a global organization.

These efficiency gains can be instrumental because ELPs have been found to result in many of the same positive outcomes associated with the implementation of RJP (Buckley et al., 1998; Buckley, Mobbs, Mendoza, Novicevic, Carraher and Beu, 2001). Additionally, in modern dynamic global environments, it may be difficult to provide job-specific details for workers whose roles are constantly evolving. In these cases, organizations may encounter difficulty in administering RJP's, but would be able to enact some of the same positive organizational outcomes through the use of ELP's. While a number of empirical studies have attempted to test the comparative effectiveness of expectation tempering in RJP and ELP (e.g., Buckley et al., 1998; Hom, Griffeth, Palich and Bracker, 1998; Pearson 1995), there have been few attempts of theoretical exploration into the underlying psychological processes that may influence why ELP operates and may be a significant addition to pre-entry and orientation phases of an organizational socialization program.

The goal of this paper is to integrate research from the fields of economics, management, and marketing in an attempt to better understand the nature of expectations and the process of their formation in RJP and ELP methods of influencing the development of realistic expectations about a foreign assignment in a multinational organization (MNC) (Coye, 2004). The logic of the paper starts with the development of a literature review of the research regarding met expectations and expectation formation. Second, the theory of Expectation Disconfirmation Theory is related it to both RJP and ELP. Borrowing from the aforementioned diverse areas, a model is developed containing a continuum of expectations, disconfirmation, satisfaction and turnover intention that provides some insight, from a theoretical perspective, regarding why RJP and ELP frequently result in successful expatriate assignments.

\section{EXPECTATION DISCONFIRMATION THEORY}

The met expectations literature within the management domain has been paralleled by a concurrent stream of research within the marketing (e.g., consumer behavior) domain where Expectation Disconfirmation Theory (EDT), introduced by Oliver (1977), examines the underlying processes that determine the effects of met and unmet expectations. This EDT theory is based on the key construct of disconfirmation, arguing that "individuals implicitly make summary comparative judgments apart from and as an input to feelings of satisfaction (Olive, 1977:461). As these judgments are made, if the perception of the experience exceeds pre-experience expectations, then positive disconfirmation will occur. If the experience is perceived as worse than expected, then negative disconfirmation will occur.

Most of the original research into expectations posited that higher expectations would yield more positive perceptions of the experience (Rosenthal, 1993). EDT does not dispute this main effect, but suggests that the disconfirmation effect will be stronger (see Figure 1). Because of the minimal direct effect of expectations, which is overpowered by the effect of disconfirmation, a number of more additional studies have omitted the direct effect of expectations on perceptions of experience, and focus only on its mediated effect through disconfirmation (Patterson, Johnson and Spreng, 1997).

While EDT was developed within the consumer satisfaction research in marketing, the same theoretical principles may be at work in determining job satisfaction of expatriate managers' adjustment and satisfaction research. The powerful effect that expectations have on our perception of on foreign assignments experiences can play a crucial role in determining job satisfaction of the expatriate manager. If one enters into a foreign assignment with inflated expectations, the expatriate is more likely to experience negative disconfirmation. This negative disconfirmation can affect the expatriate's perceptions of the job experience which, in turn, these influences can reduce job satisfaction and successfully completion of the expatriate assignment. 
Figure 1

Predictive Model

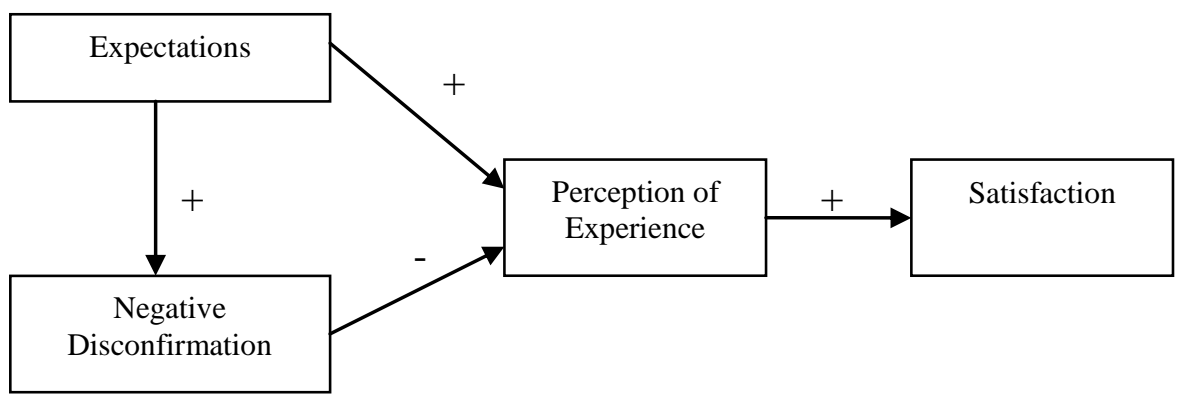

\section{PAST RESEARCH ON MET EXPECTATIONS}

Although Porter and Steers (1973) presented their in-depth analysis of turnover and absenteeism in terms of met expectations well over thirty years ago, management researchers still continue to debate the role that met expectations play in determining job satisfaction and turnover particularly in unique situations like expatriate assignments. While one group of researchers has reported significant relationships between met expectations and turnover or turnover intentions (Hom et al., 1998; Pearson, 1995; Turnley and Feldman, 2000; Watruba and Tyagi, 1991), another group of researchers has called into question the importance of met expectations, arguing that on the job experiences are significantly more important in determining job satisfaction and turnover intention (Irving and Meyer, 1994). As much of this research focused on post-entry experiences where influential variables are often confounded, it still can be interpreted as limited support for the met expectations hypothesis.

Given the partial relevance of met expectations, the issue is which expectations are to be met - those about the job or those about the self (or bots). In his early writings concerning organizational entry and RJP, Wanous (1980) made a compelling case for the important role of job-based expectations in the organizational pre-entry and orientation phases of socialization processes. He argued that unrealistic expectations about the job and its context consistently resulted in low job satisfaction. In addition, Wanous found that across studies, job satisfaction continued to decrease over time in situations where expectations were not congruent with organizational reality.

Since Wonous's original conceptualization of RJP as an intervention remedy for these problems, the underlying factors that account for its success relative to positive organizational outcomes have been debated. Other factors, such as coping strategies and perceptions of employer concern, have been postulated as possibly responsible for the effectiveness of RJP (Hom, Griffeth, Palich and Bracker, 1999). Despite some degree of disagreement concerning the role of met expectations, most of the literature is consonant with the notion that met expectations are, at least, partially responsible for the positive organizational outcomes associated with RJP. Additionally, met expectations have been shown to be positively associated with other beneficial outcomes, such as better work adjustment (Ashforth and Saks 2000; Caligiuri, Phillips, Lazarova, Tarique \& Burgi 2001) and more organizational citizenship behaviors (Turnley and Feldman 2000).

Recently, ELP has been introduced as an alternative or a compliment to RJP (Buckley et al., 1998, Buckley, Mobbs, Mendoza, Novicevic, Carraher and Beu, 2001). Although there is some empirical evidence that ELP is effective due to its influence on expectations, there has been scant theoretical explanation offered concerning this influence. The following section involves an attempt to build upon the existing met expectations literature in order to suggest a richer theoretical model of the effects of expectations in the organizational pre-entry and socialization processes. This should provide a more compelling explanation concerning how RJP and ELP influence expectations, and, through expectations, other important organizational outcomes. 


\section{EXAMINATION OF THE EXPECTATIONS FORMATION PROCESS}

For the most part, management researchers have only modestly addressed the issue of differentiated expectations and their formation process. But, there is a rich stream of literature within economics that has analyzed different processes of expectation formation (Harvey, Bolger, and McClelland, 1994). Harvey et al. (1994) identify three economic views of expectation formation: 1.) extrapolative expectations; 2.) adaptive expectations; and 3.) rational expectations. These are not categorically exclusive views; instead, each view builds upon the previous one, adding a richer, more complex understanding of how expectations are formed. This progressive perspective on expectation formation is of particular interest relative to expatriate managers given the complexity of foreign assignments and the difficulty of expatriate adjustment to both the internal and external environments. These views have been developed over time through extensive examination of factors that might play a role in determining expectation formation. Though developed in an economic context, the insights from this research stream provide valuable insight into expectation formation within an organizational context that is currently missing particularly in assignment of global context positions.

The extrapolative view of expectation formation suggests that individuals use patterns of past performance or experience to develop an expectation for future performance or experience (Vega-Redondo, 1989). This is of less value when the new experience (i.e., foreign assignment) is so different from past experiences (i.e., domestic assignments) that the expatriate manager does not have the basis to have realistic expectations. In an economic context, expatriate managers will look at previous assignments that had predictable patterns to determine future expectations relative to new assignments. Simply put, in an employment context, expatriate managers would consider past job experiences to predict future job experiences.

In this narrow view of expectation formation, expatriate managers do not consider anything other than past patterns to determine their expectations. While this is clearly one part of the information that is considered when forming expectations, this approach is also very limited and one-sided. It implies that expatriate managers will only look at their past job experiences to predict future job experiences based only on the past pattern of the job and the environmental context in which they are to fulfill the assignment. On the one hand, if expatriate's experienced consistently low job satisfaction at all of their previous jobs, expatriates' would predict that they will have low levels of job satisfaction during overseas assignments. On the other hand, if each job that an expatriate had was increasingly better, they would expect each new overseas assignment in the future to be increasingly better. While expatriates clearly consider past experiences in developing expectations of future experiences, this paints an incomplete picture of the process. Expatriates will frequently consider more than just the pattern of previous job experiences to predict future job experiences and will incorporate their expectations of the environment that they will be working in during the overseas assignment.

Having recognized the limited explanatory power of extrapolative expectation formation, economics researchers sought to develop a richer theory for expectation formation, and presented the adaptive expectations view (Harvey et al., 1994). Adaptive expectation formation takes into account that individuals may weight specific experiences more or less heavily than others in creating their future expectations. For example, an expatriates may weight the importance of a recent bad assignment as less important in predicting future assignments because of a boss one had or due to the context (environment) in which the assignment was undertaken. The expatriate has identified the recent occurrence as out of the ordinary, and therefore discounts its value in predicting future performance in an overseas context.

In an employment setting, an individual may see a recent poor job experience as an exception to the rule, and therefore still maintain relatively high expectations for a position overseas. This view acknowledges that managers utilize cognitive processes to prioritize the significance of particular experiences. Expatriate managers can be viewed to reason more as statisticians who can identify outliers or other noise in the data, correct for this and develop more appropriate expectations. While this adaptive view clearly adds a richer level of understanding of expectation formation than the extrapolative view, it still is inadequate in capturing the fullness of information that individuals typically will consider when forming expectations. It is clear that there is other relevant information beyond past experience and even relative significance of past experience that is utilized in the process of forming expectations. 
Due to the limited explanatory power of the adaptive view, economics researchers searched for a model that allows individuals to take into account all relevant information, realizing that all relevant information includes more than just past performance or selective interpretation of past performance (Harvey et al., 1994). The view that posits that individuals use all relevant information is the Rational Expectations Theory (RET). Beginning in the 1970s, the field of economics underwent what is often referred to as the "rational expectations revolution" (McCallum, 1994). Since that time, the debate over the rationality of individuals has continued (DeCanio, 1979; Feldman 1987), but a practical theory of expectation formation that is richer in information than RET has not been formulated. The realization that individuals take in a wide variety of information, analyze it in complex ways and develop expectations based on this analysis complicates our modeling of this process, but enriches our understanding of it. This enriched understanding provided by RET could be insightful as we analyze job expectation formation. Since RET acknowledges that other information outside of past performance or weighted interpretation of past performance is used in determining expectations of future performance, organizations can provide information that may shape individual expectations. Therefore, RJP and ELP can and should be viewed as valuable tools that allow organizations to provide information that influences the formation of newcomer expectations.

While originally formulated within the domain of economics, the RET may possess explanatory power to phenomena that have been observed within management domain. While past research studies have shown empirically that expectations can be lowered by pre-entry, orientation, and socialization processes (e.g., Buckley et al., 1998; Buckley et al., 2001; Wanous, 1980), these studies have not established how these processes are able to influence expectations. As the RET posits that individuals consider all relevant information in the formation of their expectations, it is necessary to examine how RJP-provided and ELP-provided relevant information is processed by an expatriate in the process of developing/forming expectations.

\section{ASSESSMENT OF THE EXPECTATIONS CONTINUUM}

Building-off of the consumer satisfaction model developed by Santos and Boote, (2003), a similar model can be proposed to represent the relationships between expectations, disconfirmation, turnover intentions and job satisfaction of expatriate managers (See Figure 2). Instead of referring to a single level of expectations, this model refers to a continuum of expectations from the ideal to the worst imaginable. This expectations continuum is aligned with three related continuums: intention to leave/stay, disconfirmation and job satisfaction.

The ideal expectation level in this model is not conceptualized as the expatriate's idea of a "dream job," but instead their idea of perfect outcome within this specific job. Most expatriates are realistic in understanding that this 'ideal' will not occur, but they still fashion a picture of what the 'ideal' would look like within their minds. Aware of what they know prior to entry into an overseas assignment, newly assigned expatriate managers form images and beliefs about the 'ideal' outcome in an international context. In theory, when an expatriate's experience matched their 'ideal', they would experience high levels of positive disconfirmation leading to high job satisfaction and high intention to stay with the organization.

Below the ideal, lies the desired outcome level. This level is viewed as a very positive job experience for the expatriates. The consumer satisfaction literature has often made a distinction between desired performance level and predicted performance level, and the results of obtaining each (e.g., Zeithaml, Berry and Parasuraman, 1993; Coye, 2004). In an international employment setting, as the expatriate realizes that the job cannot be perfect, he/she creates a level that seems more attainable as a reasonable level of expectations. This level is the outcome that the expatriate wants to occur during the overseas assignment. The important difference between the desired level and the ideal level is that the expatriate believes that the desired level is a possible outcome, while he/she is aware that the ideal level is typically unrealistic. If an expatriate experiences the desired outcome, positive disconfirmation occurs influencing other positive organizational outcomes. Job satisfaction will be high, and intent to stay with the organization will be correspondingly high reducing the tendency for higher turnover during expatriate assignments. 
Figure 2

Levels of Expectations

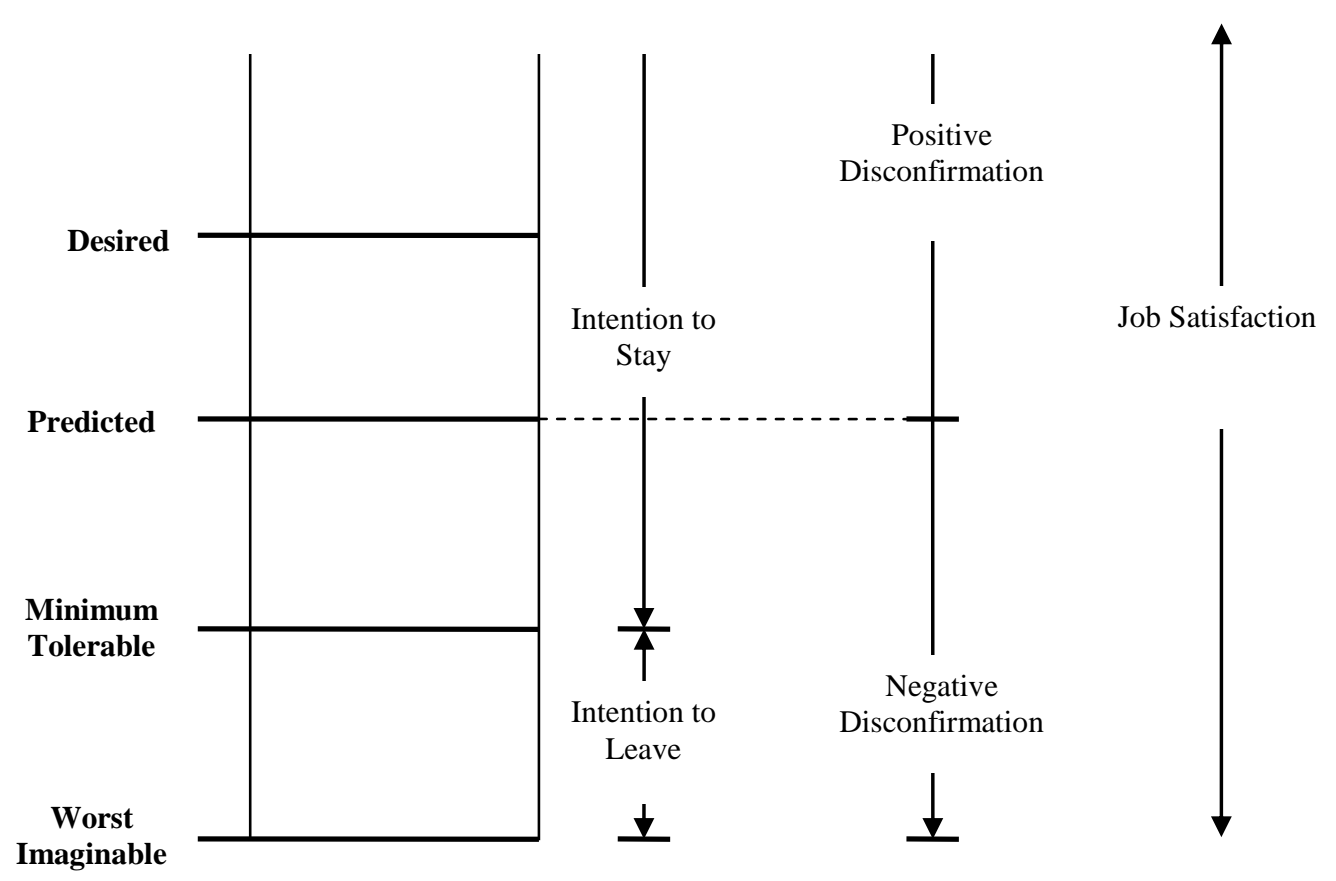

The predicted expectation level is what is most commonly conceptualized as expatriate expectations. This is the job experience that the expatriate expects they will have. This is the level that is most analyzed by the expatriate as he or she makes the decision concerning a position and an organization. It is considered the most probable outcome. In the consumer satisfaction literature, Oliver (1977) focused on this level, because it is the dividing line between positive and negative disconfirmation. If an expatriate's experiences match his or her predicted outcome, then he or she will experience confirmation. This confirmation leads to a reasonable level of job satisfaction and an intention to stay with the organization.

The minimum tolerable level exists at a level below the predicted level. This level is of great significance to management, because it is the dividing line between intention to stay and intention to leave. While the expatriate's expectations were not met at this level, the outcome would be still within tolerance; therefore, the expatriate is willing to stay with the organization. In many cases, positions and organizations do not meet the expectations of expatriate s; however, this does not always result in turnover (e.g., Buckley et al., 1998; Buckley et al., 2001). This continuum posits that expatriate $s$ are willing to stay even if the job experience does not meet their expectations as long as it does not fall below a certain minimum tolerable level. RJP and ELP lower not only the predicted expectation level, but also the minimum tolerable level, thereby reducing turnover. While expatriate's experience lower level of job satisfaction at this level and negative disconfirmation, they must fall below the minimum tolerable level, before they intend to leave the organization.

The lowest level within the expectations continuum is the worst imaginable. This is conceptualized as the worst possible job outcome considered by the expatriate. Again, this is not generalized, but related to a specific job being considered. While this is an unlikely outcome, the results of this outcome would be quite negative for both individual and organization. At this level, the expatriate experiences considerable negative disconfirmation. This disconfirmation leads to low levels of job satisfaction and a strong intention to leave the organization. 


\section{MODEL OF THE EFFECTS OF EXPECTATIONS MANAGEMENT}

As supported by rational expectation formation theory and empirical studies (Buckley et al., 1998; Buckley et al., 2001), RJP and ELP are proposed to have a direct negative effect on expatriate expectation levels. RJP's and ELP's both provide information to the expatriate, which can be taken into account when developing expectations. Though the information provided by RJP's and ELP's is different, both procedures help expatriate s create a more accurate idea of their future job experience. According to the rational expectation formation theory, expatriates are able to process the information provided and adjust their expectations accordingly. Since expectations tend to be inflated prior to job entry, RJP's and ELP's lower expectations. The proposed model (see Figure 3) shows both of these negative relationships.

Proposition ${ }_{1}:$ Both RJP's and ELP's will have a negative relationship with expectation levels of expatriate managers.

Figure 3

Explanatory Model

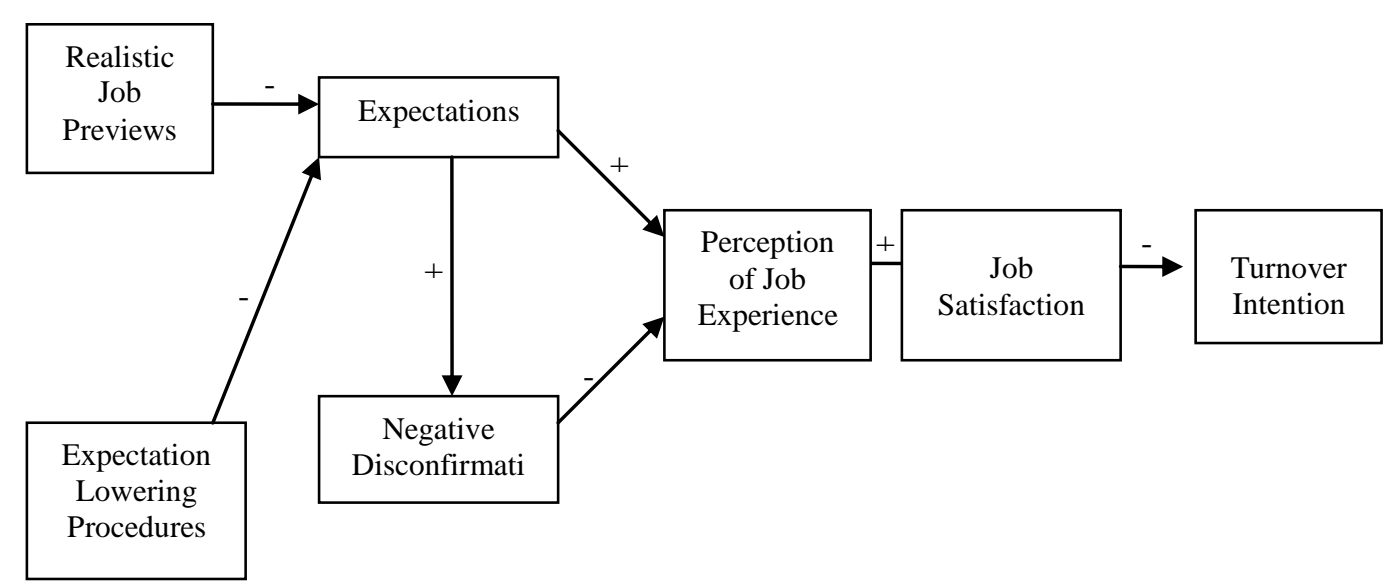

Next, the model illustrates the proposed positive direct effect of expectations on the perception of the job experience, as supported by cognitive psychological theory (Rosenthal, 1993) and EDT (Oliver, 1977). Importantly, however, the effect that expectations have mediated through negative disconfirmation is likely to be stronger than this direct effect. The relative strength of these two effects is why RJP and ELP have the hypothesized, apparent, and desired effect on important human resources outcomes (e.g., job satisfaction and turnover).

As shown, expectations are proposed to have a positive relationship with negative disconfirmation. This relationship has been found repeatedly in the consumer satisfaction literature (e.g., Churchill and Suprenant, 1982; Oliver, 1977; Oliver, 1980). As expectations rise, negative disconfirmation increases, while as expectations fall, negative disconfirmation decreases. In turn, negative disconfirmation has a negative effect on the expatriate's perception of the job experience. Again, this negative effect of disconfirmation on perception of experience is stronger than the positive effect of expectations on perception of experience. For this reason, higher expectations ultimately result in a less positive perception of the job experience. Thus, organizations that utilize RJP and ELP will facilitate more positive perception of job experience among their expatriates. 
Proposition $_{2 a}$ : Expectations will have a positive direct effect on expatriate's perception of a job experience.

Proposition $_{2 b}$ : Expectations will be positively related to negative disconfirmation of the expatriate manager.

Proposition $_{2 c}$ : Negative disconfirmation will be negatively related to an expatriate 's perception of a job experience.

Proposition ${ }_{2 d}$ : The mediated negative effect of expectations on an expatriate's perception of their job experience through negative disconfirmation will be stronger than the positive direct effect.

A more positive perception of the job experience is proposed to lead to higher levels of job satisfaction (Caligiuri, Phillips, Lazarova, Tarique \& Burgi 2001). This relationship between perception of the experience and satisfaction has been shown to hold within consumer satisfaction research (Oliver, 1977). Management research has also found a significant positive relationship between perception of job experience and job satisfaction (Irving and Meyer 1994). As expatriate perceive, the experience to be better, they are more satisfied with the job, while as expatriates perceive the experience to be worse, they may be less satisfied with the job.

Finally, and probably of most significance to the organization, higher job satisfaction, leads to lower turnover intentions (Caligiuri, Phillips, Lazarova, Tarique \& Burgi 2001). This connection means that the time and money invested in providing RJP and ELP yields tangible results to an organization. As the costing of human resources literature indicates, turnover reduction means "bottom-line" savings for the organization (Cascio, 2000).

Proposition 3 : Better perceptions of an overseas experience are proposed to reduce turnover intentions of expatriate managers through their effect on job satisfaction.

This model shows how RJP and ELP, through their influence on expectations, may effectively increase job satisfaction and decrease turnover. This model does not assume that the only way that RJP and ELP elicit these outcomes is through expectations, but instead that this is a primary way that these outcomes are accomplished. Others have proposed that RJP produces these valuable outcomes, through self-selection, perceptions of employer honesty, and/or coping skills (Breaugh, 1983; Breaugh and Starke, 2000; Hom et al., 1999). The model proposed in this paper does not refute that these other factors may also contribute to the positive value of RJP and encourages future research to explore the theoretical processes that might underlie these processes as well.

This paper is an important initial attempt at placing the applied success of ELP in a theoretical context. This will hopefully facilitate both future research and application on this emerging intervention (Breaugh and Starke, 2000). We believe that an ELP should be considered both a compliment to and a substitute for an RJP.

\section{CONCLUSION}

The expatriate assignments of traditional length convey expectations consistent with and supportive of established goals and standards (i.e., expatriates demonstrate their acquired competence by reporting within the preestablished formats and by meeting the pre-established performance criteria) may be in a dramatic state of flux at the present times of salient globalization. Increasingly, expatriate learning evolves in a dynamic manner with a content divided into specific projects. The projects such as IJVs, IM\&As, and post-acquisition integration are set per the headquarters standards focusing the expatriate (and the corporate HR management's) attention on limited scope of activities. Such a directed approach to assignment management focuses expatriate attention both to pre-determined, "target" expectations relative to performance goals and to evolving "purpose" expectations related to learning outcomes from the assignment experience.

With the dramatic growth of knowledge-based competition that requires continuous expatriate and organizational learning, HR managers are challenged to design systems capable of administering and managing effectively and simultaneously both the assignment dynamics and the expatriate expectations. Given the increased access to new, interactive communication technologies and solutions that support high expatriate involvement in virtual interactions across the firm, the challenge of an assignment management is exacerbated for the corporate HR 
function as expatriates may likely inflate their expectations about their involvement, contribution and performance in complex assignments. Expatriate expectations become particularly unrealistic in exploratory and learning-intensive assignments involving IJV or post-acquisition integration because such assignment design emphasizes intentional learning and active expatriate engagement in the cognitive management processes of data, information, and knowledge compilation, evaluation, manipulation and generation (Thaler, 1985). As the expatriates' purposeful, effortful, self-regulated, and active engagement in the assignment process increases so do their perceptions of entitlement to a higher status.

The practitioner-oriented literature of assignment management is replete with descriptions of many technology-intensive systems that enable very efficient assignment administration, asserting a potential to motivate expatriates to grow and to function in a manner that enhances their learning outcomes. However, the negative externalities of the expatriate enabling potential for learning, in the form of expatriate unrealistic expectation formation, have been curiously unattended in past HR practice. The critical task of the corporate HR management is to intervene appropriately and align the expatriate assignment contingencies in a manner that suppresses formation of expatriate unrealistic expectations. Such interventions insure appropriate expatriate goal orientation and performance adaptability to yield successful learning outcomes for the firm.

This paper not only fills in this gap in past international human resource management research but also recommends specific theory-based, yet practical ways of intervening to suppress expatriate entitlement formation process. The following managerial recommendations are made:

- $\quad$ Expatriate managers should be informed of the difficulties associated with their potential assignment when they are being selected, providing an "out" for them if they do not want to undertake an overseas assignment.

- $\quad$ Once selected for an overseas assignment, expatriate managers should be clustered into categories by their levels of expectations relative to their assignments. Each group of expatriates based upon their level of expectations will be provided with different training and expectation lowering programs.

- Given the different categories of expectations of expatriate managers, various levels of interventions will be used to help align their expectations with the 'reality' of their assignments.

- $\quad$ Once upon assignment the actual level of culture shock and alienation should be determined for each expatriate manager for the macro as well as the organization culture.

- $\quad$ Custom communications efforts/channels should be developed to help implement successful interventions with expatriates to bring their expectations into line with the actual overseas assignment.

- $\quad$ After an expectation lowering intervention, management will need to follow-up with managers to insure that the recommended level of expectation lower has occurred.

If expatriate expectations are properly managed, following the framework of the Assignment Intervention Matrix suggested in this paper, the expatriates will likely suffer less from common "learning disabilities" - those that limit their capability to properly leverage their acquired integration-related competencies for the benefit of organizational learning. In other words, effective management of expatriate unrealistic expectations in dynamic and complex assignments is critical for their learning outcomes to augment the firm knowledge stock and flows.

\section{REFERENCES}

1. Ashforth, B. E. \& A. M. Saks (2000). Personal Control in Organizations: A Longitudinal Investigation with Newcomers. Human Relations, 53 (3), 311-339.

2. Breaugh, J. A. (1983). Realistic Job Previews: A Critical Appraisal and Future Research Directions. Academy of Management Review, 8 (4), 612-619.

3. Breaugh, J. A. \& M. Starke. (2000). Research on Expatriate Recruitment: So Many Studies, So Many Remaining Questions. Journal of Management, 26 (3), 405-434.

4. Buckley, M. R., D. B. Fedor, J. G. Veres, D. S. Wiese \& S. M. Carraher. (1998). Investigating Newcomer Expectations and Job-Related Outcomes. Journal of Applied Psychology, 83 (3), 452-461.

5. Buckley, M. R., T. A. Mobbs, J. L. Mendoza, M. M. Novicevic, S. M. Carraher \& D. S. Beu. (2002) Implementing Realistic Job Previews and Expectation-Lowering Procedures: A Field Experiment. Journal of Vocational Behavior, 61, 263-278. 
6. Caligiuri, P. J. Phillips, M. Lazarova, I Tarique \& P Burgi (2001). The Theory of Met Expectations Applied to Expatriate Adjustment: The Role of Cross-Cultural Training, International Journal of Human Resource Management, 12 (3): 357-372.

7. Cascio, W. F. (2000). Costing human resources, New York: Southwestern.

8. Churchill, G. A. and C. Surprenant. (1982). An Investigation Into the Determinants of Customer Satisfaction. Journal of Marketing Research, 19 (4), 491-504.

9. Coye, R. W. (2004). Managing customer expectations in the service encounter, International Journal of Service Industry Management, 15 (1): 54-71.

10. DeCanio, S. J. (1979). Rational Expectations and Learning from Experience. The Quarterly Journal of Economics, 93 (1), 47-57.

11. Feldman, M. (1987). An Example of Convergence to Rational Expectations with Heterogeneous Beliefs. International Economic Review, 28 (3), 635-650.

12. Harvey, N., F. Bolger and A. McClelland. (1994). On the Nature of Expectations, British Journal of Psychology, 85, 203-229.

13. Hom, P. W., R. W. Griffeth, L.E. Palich \& J. S. Bracker. (1998). An Exploratory Investigation into Theoretical Mechanisms Underlying Realistic Job Previews. Personnel Psychology, 51 (2), 421-451.

14. Hom, P. W., R. W. Griffeth, L. E. Palich \& J. S. Bracker (1999). Revisiting Met Expectations as a Reason Why Realistic Job Previews Work. Personnel Psychology, 52 (1), 97-112.

15. Iriving, P. G. \& J. P. Meyer. (1994). Reexamination of Met-Expectations Hypothesis: A Longitudinal Analysis. Journal of Applied Psychology, 79 (6), 937-949.

16. McCallum, B. T. Macroeconomics (1994). After Two Decades of Rational Expectations. Journal of Economic Education , 25 (3), 219-234.

17. Oliver, R. L. (1977). A Theoretical Reinterpretation of Expectation and Disconfirmation Effects on Post-purchase Product Evaluations: Experience in the Field. in Day, R. L. (ed.) Consumer Satisfaction, Dissatisfaction and Complaining Behavior. Indiana University, Bloomington, IN, 2-9.

18. Oliver, R. L. (1980). A Cognitive Model of the Antecedents and Consequences of Satisfaction Decisions. Journal of Marketing Research, 17 (4), 460-469.

19. Patterson, P. G., L. W. Johnson \& R. A. Spreng. (1997) Modeling the Determinants of Customer Satisfaction of Business-to-Business Professional Services. Academy of Marketing Science Journal, 25 (1), 4-17.

20. Pearson, C. A. L. (1995). The Turnover Process in Organizations: An Exploration of the Role of Met-Unmet Expectations. Human Relations, 48 (4), 405-420.

21. Porter, L. W. \& R. M. Steers. (1973). Organizational Work, and Personal Factors in Expatriate Turnover and Absenteeism. Psychological Bulletin, 80 (2), 151-176.

22. Rosenthal, R. Interpersonal Expectations: Some Antecedents and Some Consequences (1993). in Blanck, P. D. (Ed) Interpersonal Expectations: Theory, Research and Applications, New York: Cambridge University Press.

23. Santos, J. \& J. Boote. (2003). A Theoretical Exploration and Model of Consumer Expectations, Post-purchase Affective States and Affective Behaviour. Journal of Consumer Behaviour, 3 (2), 142-156.

24. Turnley, W. H. \& D. C. Feldman. (2000). Re-examining the Effects of Psychological Contract Violations: Unmet Expectations and Job Dissatisfaction as Mediators. Journal of Organizational Behavior, 21 (1), 25-42.

25. Vega-Redondo, F. (1989). Extrapolative Expectations and Market Stability, International Economic Review, 30 (3), 513-517.

26. Wanous, J. P. (1973). Effects of Realistic Job Previews on Job Acceptance, Job Attitudes and Job Survival. Journal of Applied Psychology, 58, 953-965.

27. Wanous, J. P. (1980). Organizational Entry: Recruitment, Selection, and Socialization of Newcomers. Reading, MA: Addison-Wesley Publishing Company.

28. Watruba, T. R. \& P. K. Tyagi. (1991). Met Expectations and Turnover in Direct Selling. Journal of Marketing, 55 (1), 24-35.

29. Zeithaml, V. A., L. A. Berry and A. Parasuraman. (1993). The Nature and Determinants of Customer Expectations of Service, Journal of the Academy of Marketing Science, 21 (1), 1-12. 